\title{
Multi-criteria evaluation and optimization of the ultrasonic sealing performance based on design of experiments and response surface methodology
}

\author{
Karlien D’huys ${ }^{1, *}$, Bram Bamps ${ }^{2}$, Roos Peeters ${ }^{2}$, Bart De Ketelaere ${ }^{1}$ \\ ${ }^{1} \mathrm{KU}$ Leuven Department of Biosystems, MeBioS, Kasteelpark Arenberg 30, B-3001 Heverlee, \\ Belgium \\ ${ }^{2}$ Hasselt University, IMO-IMOMEC, Packaging Technology Center, Martelarenlaan 42, B-3500 \\ Hasselt, Belgium \\ *Corresponding author
}

\begin{abstract}
Proper closure is an essential packaging quality aspect and can, amongst others, be achieved with ultrasonic sealing. The ultrasonic sealing performance depends on the film type and the seal settings, such as seal time, applied force and ultrasonic amplitude. Because these parameters are less intuitive than heat seal parameters and optimal settings are undefined for many films, this work presents an efficient approach to evaluate the effect of these settings on the ultrasonic sealing performance. An experimental design defines the experiments to perform. A response surface methodology is then used to model the relation between seal settings and sealing performance. Based on these models, the seal settings are optimized. As there are several criteria to express sealing performance, single- and multi-criteria optimizations are described.

The approach was illustrated for a PET/LLDPE-C4 film. The seal settings were optimized to obtain high seal strength, limited ultrasonic horn displacement and low seal energy. The optimum settings were $0.1 \mathrm{~s}$ (seal time), $4.32 \mathrm{~N} / \mathrm{mm}$ (force) and $28.75 \mu \mathrm{m}$ (amplitude). The predicted optimum strength, horn displacement and energy were $2.32 \mathrm{~N} / \mathrm{mm}, 40 \mu \mathrm{m}$ and $11.66 \mathrm{~J}$, respectively. Besides the optimum, the seal window is also of interest. A broad seal window ensures sufficient seal strength for a wide range of settings. For the PET/LLDPE-C4 film, a strength of $\geq 90 \%$ of the optimum was obtained for $39 \%$ of the input combinations within the design space.

The presented approach is widely applicable (other films, sealing processes) since it is flexible in the input parameters, design and responses.
\end{abstract}

\section{Introduction}

Packaging represents a crucial step in the processing chain of the consumer goods industry, protecting the content from its environment and preventing leakage of the contained product ${ }^{1}$. Although many different packaging types exist, there is a trend towards packaging based on semirigid and flexible materials ${ }^{2}$. Polyolefins, more specifically polyethylene (PE) and polypropylene (PP), are by far the most used sealing materials in flexible packaging. Polyolefine seal layers are 
often a blend and/or multilayer structure of several polyolefin subtypes. Moreover, they are often laminated against a layer with a higher melting temperature such as polyethylene terephthalate (PET) or oriented polyamide (oPA) to ease the processability and improve the mechanical and barrier properties of the overall film ${ }^{3}$.

Closing, or sealing, of these flexible packaging materials is achieved by creating a bond between opposing material layers. The most common method used for creating this bond is through heat sealing $^{2}$. There are several options for generating heat in the seal interface, i.e. through conduction, ultrasonic displacement, electromagnetic induction or electrical field loss. Depending on the heating principle, different sealing technologies can be distinguished: heat conductive, impulse, hot air blast, ultrasonic, induction, electrical field loss, infrared laser and hot wire sealing ${ }^{4}$. Heat conductive sealing, currently the most common sealing method, involves applying a certain combination of temperature, time and pressure of the seal jaws to two flexible film layers to create a seal in the interface. Heat conductive sealing of flexible films with polyolefin layers was extensively studied in the past decades ${ }^{5,6}$. Ultrasonic sealing has been the subject of more recent studies, in which it was considered as a possible alternative to heat conductive sealing. Several advantages of ultrasonic sealing over heat conductive sealing have been shown, such as the short sealing times, decreased thermal stress on the packaged product, the capability to seal through powder contamination, a decreased energy consumption, a narrower seal and no need for thick peel layers ${ }^{2,7-9}$. In ultrasonic sealing, sound waves in the frequency range between 20 and $40 \mathrm{kHz}$ are used to create friction and thus generate heat between two layers of packaging film. The energy introduction in the seal is achieved by means of an ultrasonic horn, oscillating with an amplitude in the range of 10-60 $\mu \mathrm{m}$, and an anvil ${ }^{2,8,10}$. By applying the oscillation for a certain period of time and with a certain force, a seal is created in the interface of two flexible films. Similar to heat conductive sealing, the combination of the seal settings (frequency, amplitude, force and time) determines the quality and performance of the ultrasonic seal. If the applied settings are insufficient to create a bond, the material remains unsealed. From a certain higher setting, a peelable seal can be obtained. By further increasing the seal settings, a tear seal can be obtained. Finally, the seal is cut through if the parameter settings are further increased ${ }^{9,10}$. Identifying the combination of seal settings that results in the desired level of seal quality and performance for a specific packaging material is challenging.

For heat conductive sealing, the effect of the sealing parameters on the seal quality was the subject of several studies ${ }^{5,6,11-15}$. In most of these studies, the effect of the sealing parameters (time, temperature and pressure) on the seal/peel strength was evaluated, and this was done by varying one of the seal parameters at a time while keeping the others constant. Meka and Stehling (1994) considered the effect of the seal parameters not only on the seal strength of PE films, but also on the seal elongation and energy ${ }^{6}$. The effect of the sealing parameters on the seal quality was also studied for ultrasonic sealing in the past, although much less extensively than for heat conductive sealing $^{7-10}$. Bach et al. (2012) stated that the most important parameters influencing the ultrasonic sealing process are the sealing time, force and the amplitude of the horn and the authors studied 
the individual effect of the sealing time and force on the seal strength of commercial polyamide/polyethylene films ${ }^{8}$. Nase et al. (2013) studied the effect of the seal force on the peel properties of polyethylene/polybutene-1 peel films and concluded that the seal force has a strong impact on those properties ${ }^{7}$. Stoehr et al. (2014) performed a parameter study to characterize the effect of amplitude, force and time on the ultrasonic sealing quality of biobased packaging films produced from poly lactic acid ${ }^{10}$. Finally, Van Oordt et al. (2014) studied the effect of ultrasonic sealing time, force and amplitude on the peel strength and behavior of polyethylene composite films. The parameter effects were studied individually, although surface plots of the combined effect of time and amplitude were also shown. The authors provided a practical guideline to identify appropriate sealing parameters, although this did not include a real optimization of the parameter settings 9 .

The most commonly applied approach of varying a single seal parameter while keeping the others constant ('one factor at a time' approach) does not allow to study interactions or simultaneous effects of several seal parameters ${ }^{16}$. Moreover, it does not result in a complete picture of the effect of all parameters on the seal quality and therefore does not allow for optimization. As an answer to this shortcoming, a few authors introduced the statistical concepts of 'design of experiments' (DOE) and 'response surface modelling' (RSM) in the field of heat conductive sealing ${ }^{16-18}$. These concepts allow for a detailed analysis of the effect of the sealing parameters, provide the capability of predicting a response of interest, and this based on an efficient use of resources (workload, time, film material ${ }^{16}$. The purpose of DOE is to set up an experiment in such a way that insight in the effect of a set of input parameters on a certain response can be gained based on a limited number of carefully selected experimental runs. RSM is based on fitting a polynomial equation to the experimental data collected according to a certain experimental design, and in that way describing the data set and predicting the response within a certain experimental region ${ }^{19}$. Dixon et al. (2006) described the use of DOE to define an acceptable window of operating conditions for the heat sealing of medical packaging. The authors set up a central composite design and considered the peel strength as the response of the RSM. No optimization was performed ${ }^{16}$. A similar approach was followed by Aiyengar and Divecha (2012) to study the effect of the seal settings on the seal strength of biaxially oriented polypropylene film, although they repeated the seal strength test ten times at each of the parameter combinations defined by a central composite design. They stated that an important characteristic of a good heat seal film is a broad seal window ${ }^{18}$. Finally, Hron and Macák (2013) used a $2^{\mathrm{k}}$ factorial design in which two levels (low and high) of each of the sealing parameters were considered, to perform a screening of the effects of the parameter settings on the seal strength ${ }^{17}$. In all three of these studies, heat conductive sealing was considered, with the seal/peel strength as a single response parameter, and no optimization was performed.

In practice, the seal strength is not the only relevant characteristic of a sealing procedure. Additional aspects may play a crucial role but were barely discussed in previous research. This study considers not only the seal strength, but also the ultrasonic horn displacement and the seal energy consumed by the ultrasonic equipment as measures of the ultrasonic sealing performance. 
The goal of this study was to develop an efficient methodology, based on the concepts of DOE and RSM, to evaluate the ultrasonic seal performance of a PET/LLDPE-C4 laminate film. Besides for evaluation purposes, the developed methodology was also used for an optimization of the seal parameters towards multiple aspects of the ultrasonic sealing performance, such as the seal strength, the displacement of the ultrasonic horn and the seal energy.

\section{Materials and methods}

\subsection{Film material}

The film material studied in this work was a polyethylene terephthalate-linear low density polyethylene PET/LLDPE-C4 laminate film. The thicknesses of both layers, as provided by the supplier, were $24 \mu \mathrm{m}$ (PET) and $40 \mu \mathrm{m}$ (LLDPE-C4). The measured total thickness of the film was $69 \pm 1 \mu \mathrm{m}$. The film was produced by blown extrusion, and subject to a corona pre-treatment and lamination with Adcote ${ }^{\mathrm{TM}}$ 301/350. The film was selected since PE is a sealing medium that is commonly used in commercial packaging films. The PET outer layer is present to improve the mechanical and barrier properties of the film.

\subsection{Ultrasonic sealing and seal performance tests}

The ultrasonic seal samples were prepared with a $35 \mathrm{kHz}$ TSP750E-100-1 ultrasonic sealing device (Telsonic Ultrasonics, Switzerland) equipped with a 75x5 mm rectangular, flat surface sonotrode. An anvil with a semi-cylindrical energy director with a radius of $2.5 \mathrm{~mm}$ was used. After sealing, a holding time of $0.5 \mathrm{~s}$ and a holding force of $2 \mathrm{~N} / \mathrm{mm}$ were applied to the seal. The most important parameter settings that have to be selected before sealing are the time, the force and the amplitude.

In this research, three main characteristics of the seal samples were measured in order to evaluate the ultrasonic sealing performance of the packaging films: the seal strength, the displacement of the ultrasonic horn and the energy consumption during sealing.

The seal strength $\left[\mathrm{N} . \mathrm{mm}^{-1}\right]$ of all samples was tested using a $10 \mathrm{M}$ universal testing machine (MTS Systems Corporation, USA) equipped with a $2 \mathrm{kN}$ load cell. The measurements were performed after conditioning the samples at $23{ }^{\circ} \mathrm{C}$ and $50 \%$ relative humidity for 24 hours. A 15 $\mathrm{mm}$ wide sample was cut from the center of every $75 \mathrm{~mm}$ wide seal. Both ends of this $15 \mathrm{~mm}$ wide part were clamped at a distance of $10 \mathrm{~mm}$. Next, a tensile test was performed with a speed of 300 $\mathrm{mm} \cdot \mathrm{min}^{-1}$. The maximum strength value encountered in the tensile curve $[\mathrm{N}]$ was divided by the width of the seal sample $(15 \mathrm{~mm})$ to obtain the seal strength $\left[\mathrm{N} . \mathrm{mm}^{-1}\right]$. The tensile tests were performed according to ASTM guideline F88/F88M-15 ${ }^{20}$.

The horn displacement $[\mu \mathrm{m}]$ is the maximum travel distance of the ultrasonic horn in the sample. During ultrasonic sealing, the seal material melts and the horn travels deeper into the sample. As a result, the sealed film becomes compacted until a certain maximum value. This maximum value is registered by the ultrasonic sealing device and can be used to describe the ultrasonic sealing performance of a film material. 
Finally, the energy consumption $[\mathrm{J}]$ is the amount of energy consumed by the ultrasonic sealing device during sealing, and is calculated as the area under the power [W] versus time [s] curve of the sealing process. In the first phase of the sealing process, power builds up. Next, when the seal medium starts to melt, the power decreases. Similar to the horn displacement, the value of the energy consumption is also derived from the output of the ultrasonic sealer.

\subsection{Experimental design and seal optimization}

In this work, an efficient methodology is proposed to evaluate and optimize the ultrasonic seal performance of a PET/LLDPE-C4 film. This methodology consists of five subsequent steps:

Step 1. Firstly, the experimental design space has to be defined. This means that the parameters that have the largest influence on the seal performance must be identified and for each of these parameters the boundaries within which they can be varied should be listed. In the case of ultrasonic sealing, the seal time, seal amplitude and seal force were identified as the most relevant parameters that need to be set when creating a seal. In order to determine the minimum and maximum values to consider for these parameters, preliminary experiments were performed.

Step 2. Next, an experimental design has to be set up that defines at which combinations of the input parameters, i.e. at which locations within the design space, experiments should be performed. The type of experimental design that is most suited depends on several aspects, such as the type of model one expects will provide an adequate description of the data (e.g. only main effects or also quadratic effects, including interactions or not, ...), the number of measurements that is feasible to perform, the number of input parameters, etc. In this study, an experimental design consisting of 15 well-chosen combinations of the seal time, seal force and seal amplitude was set up. These 15 settings were selected according to a Box-Behnken experimental design in order to efficiently obtain as much information as possible on the effect of the sealing parameters based on a limited amount of experiments. Such a Box Behnken design is appealing in this context because it allows to fit a full Response Surface Model (RSM) including interactions and quadratic effects and thus allows for finding the optimal ultrasonic setting ${ }^{21}$. Furthermore, this type of design can be generated using any statistical software, or even by hand when the minimal and maximal values of the parameters are given. As such, even non-specialists in the field of experimental design have easy access to them. The order of the experimental runs was randomized so to minimize the unwanted effect of unknown disturbing factors. At each of the 15 parameter settings, an ultrasonic seal was created and its seal performance was measured as described earlier.

Step 3. Once the seal performance at each of the settings defined by the experimental design is known, a Response Surface Model can be fit to these values. In this study, a quadratic model of the following form was considered: 


$$
\begin{gathered}
y=\beta_{0}+\beta_{1} x_{1}+\beta_{2} x_{2}+\beta_{3} x_{3}+\beta_{12} x_{1} x_{2}+\beta_{23} x_{2} x_{3}+\beta_{13} x_{1} x_{3}+\beta_{11} x_{1}^{2}+\beta_{22} x_{2}^{2} \\
+\beta_{33} x_{3}^{2}+\varepsilon
\end{gathered}
$$

with $x_{1}, x_{2}$ and $x_{3}$ the three input parameters seal time, amplitude and force, $y$ the response of interest, e.g. the seal strength ${ }^{22}$, and $\varepsilon$ the error term. Besides the main effects, the interaction terms and quadratic terms were also considered in the model. In order to identify significant effects, an all possible subsets procedure was followed and non-significant effects were removed from the prediction mode ${ }^{23}$. The best subsets approach for variable selection allows to identify the model that fits best from all possible subset models, i.e. from all possible models including a certain combination of the effects described in the formula above. Several criteria can be used for variable selection, such as the R-square, the Akaike information criterion (AIC) and the Bayesian information criterion (BIC) ${ }^{24}$. In general, a model with a high R-square and a low AIC and BIC should be preferred. The Rsquare provides information on the goodness of fit of the model. The AIC holds information on the quality of the model relative to that of other models and rewards goodness of fit. However, the AIC also includes a penalty for the number of parameters in the model and thus discourages overfitting of the data. The BIC holds information that is similar to the AIC, but overfitting of the data is more severely discouraged by the BIC than by the $\mathrm{AIC}^{25}$. Often, these different selection criteria do not hold exactly the same information, i.e. they do not necessarily all point towards exactly the same model. However, they provide an adequate guideline for model selection.

Step 4. Once the most suited regression model has been selected, this model allows to predict the response (e.g. seal strength) for every possible combination of the input parameters (seal time, amplitude and force). This knowledge can then be used to find the combination of input settings that results in the desired value of the response based on the use of desirability functions. This desired value can be a maximum, a minimum or a specific target value, each corresponding to a specific shape of the desirability function. Moreover, desirability functions of any arbitrary shape can be defined. If the goal is to maximize the seal strength, for example, the desirability function can be defined as a linear increase between the minimum seal strength (desirability $=0$ ) and the maximum seal strength (desirability $=1$ ). It is not only possible to optimize the input parameters with respect to a single response variable, but also with respect to multiple responses. In this case, an individual desirability function is first defined for each of the responses (e.g. seal strength, horn displacement and seal energy). Next, an overall desirability function is defined as the geometric mean of these individual desirability functions and the responses are optimized taking into account this overall desirability ${ }^{19}$. This overall desirability equals 0 if at least one of the individual desirabilities equals 0 .

Step 5. The final step of the efficient optimization procedure involves performing confirmation experiments (10 runs) at the defined optimal settings in order to validate the model obtained. To assess the success of the confirmation, the CICon approach, as suggested by 
Antony (2003) and Jensen (2016), was followed. In this approach a confidence interval is calculated based on the confirmation runs, using the following formula:

$$
\overline{y_{c}} \pm t_{1-\alpha / 2, c-1} s_{c} / \sqrt{c}
$$

with $c$ the number of confirmation runs, $\overline{y_{c}}$ the mean of the confirmation runs and $s_{c}$ their standard deviation. If the predicted value of the optimum falls within the confidence

interval of the confirmation runs, the confirmation is considered successful ${ }^{26,27}$.

All statistical analyses were performed in the software package JMP Pro 12 (The SAS Institute Inc., USA). A significance level $\alpha$ of 0.05 was used in the entire paper, unless indicated otherwise.

\subsection{Seal window calculation}

In practice, it is not only relevant to identify a certain setting at which a packaging film will show high seal performance. Another important aspect is to study how sensitive the seal performance is to slight changes in the seal settings. This aspect was translated into a quantitative measure, which is here defined as the 'seal window'. In this work, the seal window is quantitatively expressed as the percentage of the entire design space within which the seal strength reaches a value of $90 \%$ of the optimum seal strength, or larger. The window is calculated by setting up a narrow grid of the input parameters (time, force and amplitude) over the design space, and calculating the seal strength at each grid point by evaluating the response surface prediction model. If the predicted value is within $90 \%$ of the predicted optimum seal strength, it is considered to be part of the seal window. The larger the region of the design space within which a near-optimum seal strength is obtained, the less sensitive the film is to (small) changes in seal settings. A similar seal window could also be calculated for other responses, such as the horn displacement and the seal energy.

\section{Results and discussion}

In this section the different steps of the design of experiments and response surface methodology as described in Section 2.3 are illustrated for the PET/LLDPE-C4 film. Moreover, the seal window of this film is also discussed.

\section{Step 1. Design space}

The input parameters considered in the optimization study were the seal time, the applied force and the amplitude. Based on preliminary experiments, the limits of the design space were selected as follows: the minimum values were set at the parameter combinations at the border of unsealed/peelable seal and the maximum values were set at the parameter combinations at the border of tear seal/cut through. The parameter ranges thus obtained are 0.1 to $0.3 \mathrm{~s}$ (seal time), 2 to $6 \mathrm{~N} \cdot \mathrm{mm}^{-1}$ (seal force) and 18 to $36 \mu \mathrm{m}$ (amplitude). These ranges show a large overlap with the settings applied in previous research on similar flexible films with polyolefin layers ${ }^{7,8}$. 


\section{Step 2. Experimental design and runs}

Within these limits of the design space, 15 seal setting combinations were defined according to a three-factor, three-level Box-Behnken experimental design. In Table 1, the 15 design settings together with their output for the seal performance responses (seal strength, horn displacement and seal energy) for the PET/LLDPE-C4 film are listed.

\section{Step 3. Response surface model}

In the next step, a response surface model was fitted for each of the three response parameters (seal strength, horn displacement and seal energy) and a selection of the significant terms was performed as described in Section 2.3. The regression equation, significant coefficients, terms and fit statistics of the models obtained are shown in Table 2, Table 3 and Table 4 for the seal strength, the horn displacement and the seal energy, respectively. In Figure 1, a graphical representation of the response surface models for seal strength, horn displacement and energy as a function of the force and amplitude is shown (seal time $=0.2 \mathrm{~s}$ ). The seal strength model includes a first order effect of force and a quadratic effect of amplitude. Time is not included in the seal strength model. As shown in Figure 1, the seal strength increases with an increasing force. The seal strength increases quadratically with an increasing level of amplitude. The horn displacement model includes first order effects of force and amplitude, and an interaction effect of force and amplitude. As shown in Figure 1, the horn displacement increases towards higher levels of force and amplitude. The seal energy model includes first order effects of time and force, a quadratic effect of amplitude, and interaction effects of time and force and of time and amplitude. As shown in Figure 1, the energy consumed by the sealing process increases when force and amplitude values are higher.
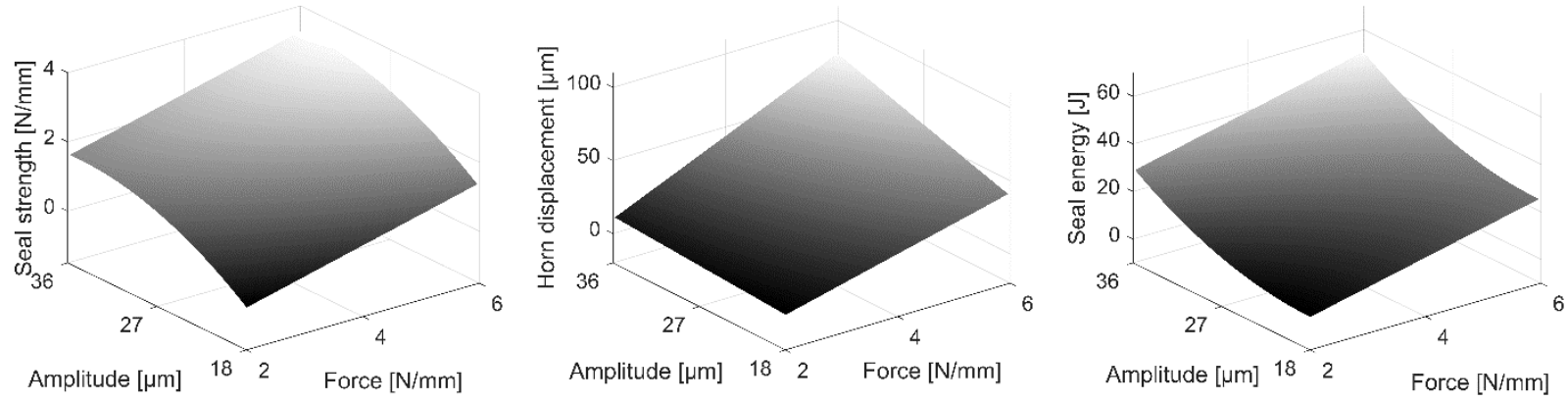

Figure 1: Response surface model for seal strength, horn displacement and seal energy as a function of force an amplitude (seal time $=0.2 \mathrm{~s}$ ) for the PET/LLDPE-C4 film.

\section{Step 4. Optimization procedure}

The response surface models described in the previous section allow to predict the seal performance responses (seal strength, compaction and energy) for every possible combination of the input parameters (time, force and amplitude) within the limits of the design space. In this section, it is described how the response surface models can be used to optimize the seal settings 
to obtain an optimum seal performance. In a first case, only a single response (seal strength) is considered, while in the second case, a multiple response optimization is illustrated.

\section{A. Single response}

In Figure 2, the optimization of force and amplitude settings to obtain a maximum seal strength is illustrated. The two columns on the left-hand side of the graph represent the influence of force and amplitude on the seal strength. The column on the right-hand side shows the desirability function for seal strength. Since the objective in this first case was to maximize the seal strength, the desirability function was defined as a linear increase from the lowest seal strength level (desirability $=0$ ) to the highest seal strength level (desirability $=1$ ). Next, the desirability was maximized, resulting in a seal strength of $3.29 \mathrm{~N} / \mathrm{mm}$ for a seal force of $6 \mathrm{~N} / \mathrm{mm}$ and an amplitude of $35.12 \mu \mathrm{m}$. These optimal settings, together with the predicted value of the optimum, are highlighted in red.

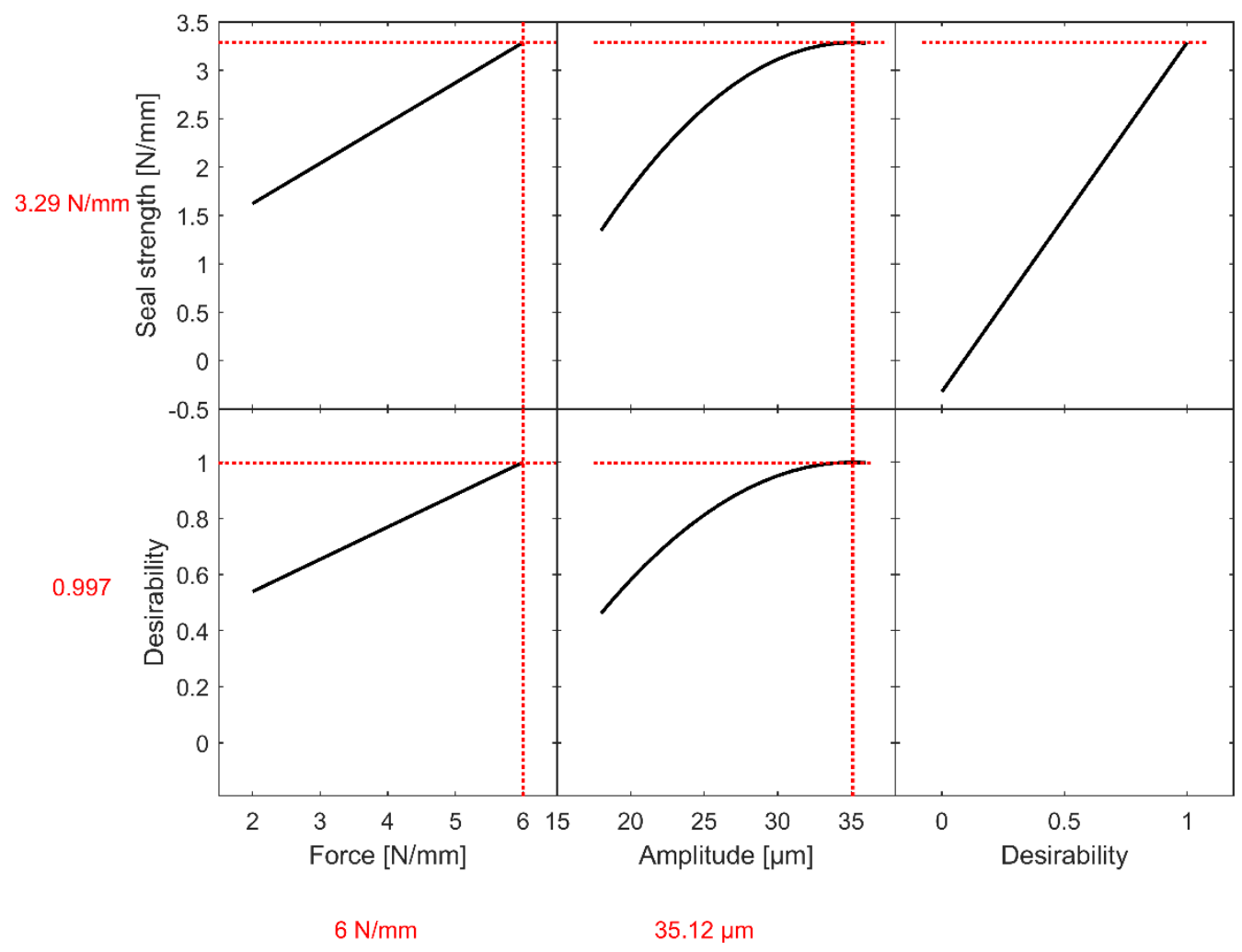

Figure 2: Profiler and desirability plot for the optimization towards seal strength only. The optimum and the optimal settings for force and amplitude are highlighted in red.

\section{B. Multiple responses}

The seal strength is not the only parameter providing relevant information about the seal quality/seal performance. Therefore, in this section the other parameters are also taken into account in the optimization. 
Firstly, a combined optimization taking into account both seal strength and horn displacement was performed. In Figure 3, the desirability plots for this two-response optimization are shown. The desirability plot for seal strength consists of a linear increase from low seal strength to high seal strength, as stated earlier. The desirability function for horn displacement has a different shape. A very large horn displacement, i.e. almost all of the sealant material has been squeezed out during sealing, is unwanted since there is a risk of completely destroying or cutting through the seal. Therefore, a step-shaped desirability function was defined, assigning a desirability ' 1 ' to horn displacement levels ranging from 0 to $40 \mu \mathrm{m}$ and a desirability ' 0 ' to horn displacement levels larger than $40 \mu \mathrm{m}$. In this way, it was defined as desirable to have at least $50 \%$ of the original thickness of the seal layer left in the final seal. As described in Section 2.3, an overall desirability function was defined as the geometric mean of these individual desirability functions and the responses were optimized taking into account this overall desirability. In this way, an optimized seal strength level of $2.40 \mathrm{~N} / \mathrm{mm}$ and a horn displacement of $40 \mu \mathrm{m}$ were obtained. The settings at which these optimized responses were achieved are $4.07 \mathrm{~N} / \mathrm{mm}$ (seal force) and $31.45 \mu \mathrm{m}$ (amplitude). By taking into account both responses in the optimization, a compromise was calculated that results in desirable results for both. 


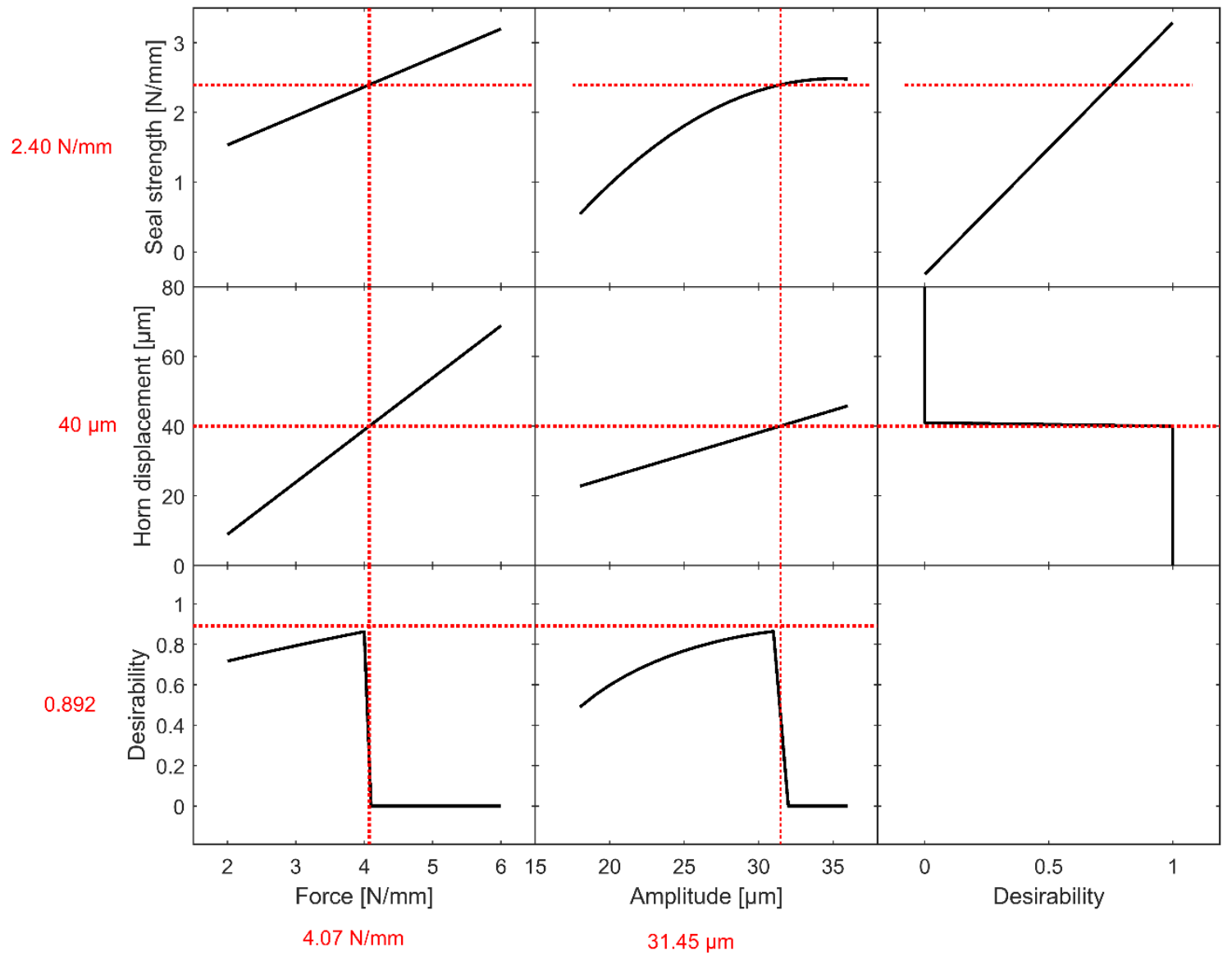

Figure 3: Profiler and desirability plot for the combined optimization towards seal strength and horn displacement.

The optimum and the optimal settings for force and amplitude are highlighted in red.

Secondly, a combined optimization taking into account seal strength, horn displacement and seal energy was performed. In Figure 4, the desirability plots for this three-response optimization are shown. The desirability plots for seal strength and horn displacement were identical to the ones used in the two-response optimization. The desirability function for seal energy consists of a linear decrease from high seal energy levels (desirability $=0$ ) to low seal energy levels (desirability $=1$ ). In this way, an optimal combination of seal settings was identified to achieve a seal strength that is as high as possible, a horn displacement that is limited and a seal energy that is as low as possible. An optimum seal strength of $2.32 \mathrm{~N} / \mathrm{mm}$, an optimum horn displacement of $40 \mu \mathrm{m}$ and an optimum seal energy of $11.66 \mathrm{~J}$ were obtained at a combination of seal settings of $0.1 \mathrm{~s}$ (seal time), 4.32 $\mathrm{N} / \mathrm{mm}$ (seal force) and $28.75 \mu \mathrm{m}$ (seal amplitude). Again, a compromise was calculated that took into account all three of the desirability functions. 


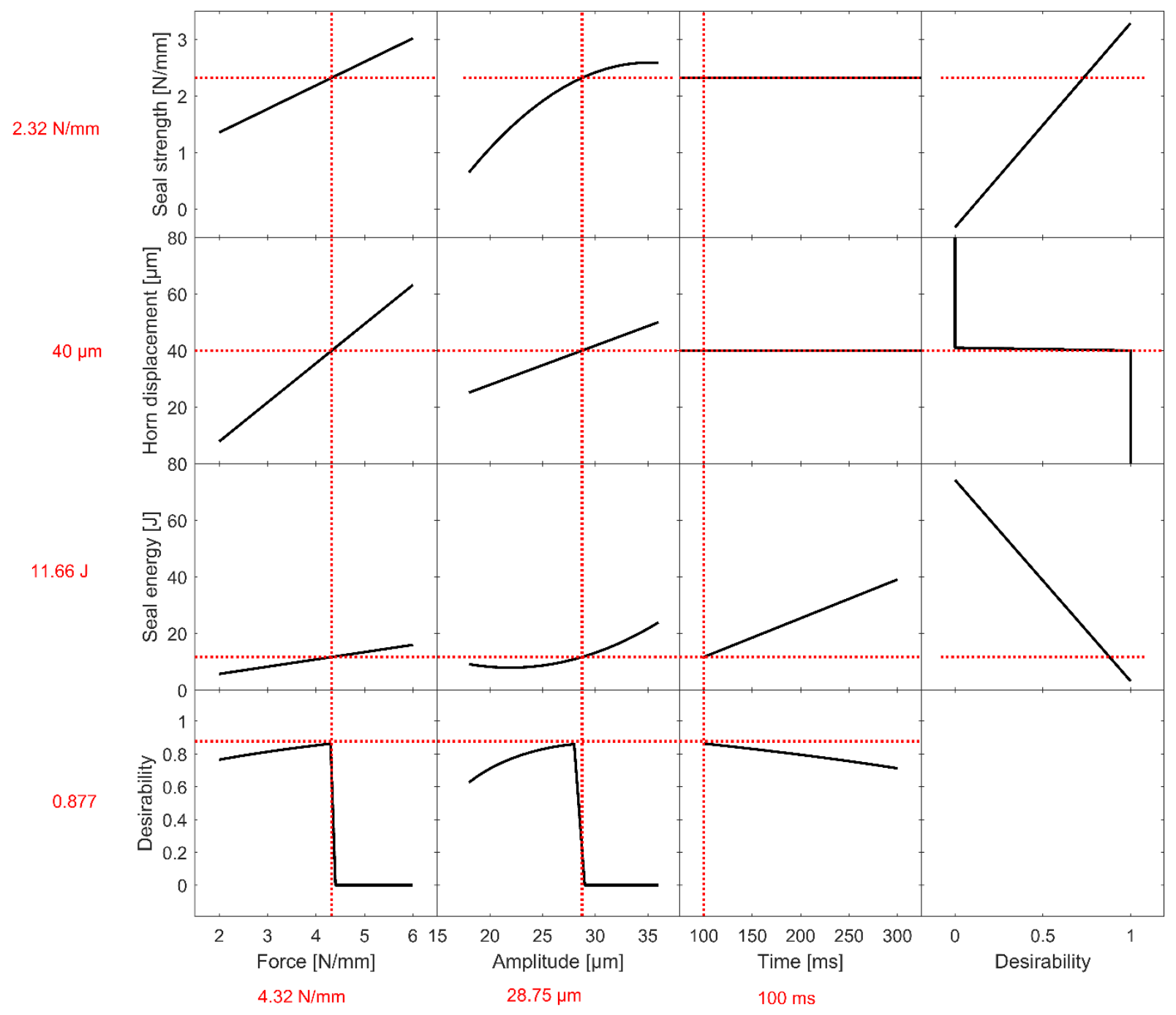

Figure 4: Profiler and desirability plot for the combined optimization towards seal strength, horn displacement and seal energy. The optimum and the optimal settings for force, amplitude and time are highlighted in red.

\section{Step 5. Optimized seal settings and experimental validation}

Since in addition to the seal strength, in practice both the horn displacement and seal energy are also relevant, the multi-response optimization presented in the previous section was considered as a suitable approach to optimize the seal settings. Validation experiments were performed at the optimum ultrasonic sealing settings. In Table 5, the results of these validation experiments are summarized. The predicted optima and the results of the confirmation runs were tested for significant differences as described in Section 2.3. On a significance level of 0.05 , predicted and confirmed optima were different for both the seal strength and the seal energy but not for the horn displacement. On a significance level of 0.10 , there were no significant differences between predicted and confirmed optima for any of the output parameters considered. If significant differences are obtained between model and test results, the underlying process is probably more 
complex than the chosen response model can describe, and more advanced designs that can take into account this more complex behavior should be considered.

\subsection{Seal window}

In Figure 5, the seal window for the PET/LLDPE-C4 film is illustrated. As stated in Section 2.4, this seal window corresponds to all combinations of input parameters (time, force, amplitude) within the considered design space that result in a seal strength of at least $90 \%$ of the optimum seal strength.

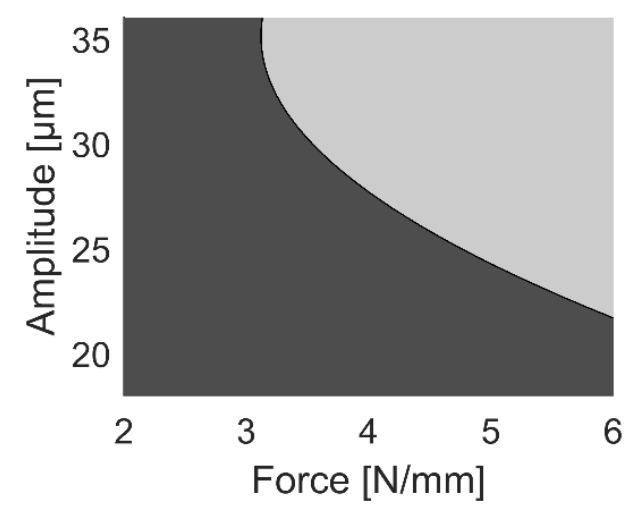

Figure 5: Seal window of the PET/LLDPE-C4 film. The light grey area indicates all combinations of the input parameters force and amplitude within the considered design space that result in a seal strength value of at least $90 \%$ of the optimum seal strength. The seal time was shown to have no significant effect on the seal strength for this film.

For this film, the seal window corresponds to all combinations of the input parameters that result in a seal strength of $2.09 \mathrm{~N} / \mathrm{mm}$ or more. A seal strength of $2.09 \mathrm{~N} / \mathrm{mm}$ or more is obtained for $39.41 \%$ of the input parameter combinations in the considered design space. A broad seal window is in general a desired characteristic of a packaging film, since it ensures sufficient seal strength even in the case of (slightly) deviating seal settings. Since time was shown to have no significant effect on the seal strength, the seal window was shown as a function of force and amplitude only.

\section{Conclusions}

In this work, a framework based on the principles of design of experiments and response surface modeling was presented to optimize the ultrasonic sealing performance of a PET/LLDPE-C4 flexible film laminate.

Based on a limited number of experimental runs, defined according to an efficient Box-Behnken experimental design, response surface models of the seal strength, the horn displacement and the seal energy as a function of the seal settings (time, force and amplitude) were built. Next, these models were used to calculate the optimal combinations of seal settings resulting in (1) maximum seal strength, (2) maximum seal strength and a value of the horn displacement below a certain limit and (3) maximum seal strength, a horn displacement below a certain limit and minimum energy use of the sealing process. In the case of the multiple output optimizations, a compromise was obtained by assigning the same weight to each of the different outputs. 
Since all three of the outputs are relevant in practice, the combined optimization towards strength, horn displacement and energy was selected as the most relevant and was experimentally validated. The predicted optimum was obtained at a seal time of $0.1 \mathrm{~s}$, a seal force of $4.32 \mathrm{~N} / \mathrm{mm}$ and a seal amplitude of $28.75 \mu \mathrm{m}$. The predicted optimum seal strength was $2.32 \mathrm{~N} / \mathrm{mm}$, the horn displacement $40 \mu \mathrm{m}$ and the seal energy $11.66 \mathrm{~J}$. The confirmation runs performed at this optimum resulted in a horn displacement that was not significantly different $(\alpha=0.05)$ from the predicted value and in a seal strength and seal energy that were not significantly different $(\alpha=0.1)$ from the predicted values. In practice, not only the optimum is of interest, but also the seal window. The seal window was defined as the region of the considered design space within which the seal strength achieved is at least $90 \%$ of the optimum seal strength. For the PET/LLDPE-C4 film, a seal strength of $90 \%$ of the optimum or more was obtained for $39 \%$ of the input parameter combinations within the design space. A broad seal window is a desired characteristic of a packaging film, since it ensures sufficient seal strength even in the case of (slightly) deviating seal settings.

Although illustrated for a single film and a single sealing process, the framework presented in this paper has a broad applicability towards other film types and sealing processes. The methodology is flexible with respect to the definition of the input parameters and the design space, the considered output parameters and the type of desirability functions.

\section{Acknowledgements}

This research was performed within the TETRA project nr. 140313 'ULTRASEAL: The potential of ultrasonic sealing in packages', funded by Agentschap Innoveren \& Ondernemen (VLAIO).

\section{References}

1. Robertson GL. Food Packaging: Principles and Practice. 2nd ed. Boca Raton: CRC Press; 2006.

2. Dudbridge M. Handbook of Seal Integrity in the Food Industry. West Sussex: John Wiley \& Sons, Ltd.; 2016.

3. Hishinuma K. Heat Sealing Technology and Engineering for Packaging: Principles and Applications. Lancaster: DESTech Publications Inc.; 2009.

4. Coles R, McDowell D, Kirwan MJ. Food Packaging Technology. Oxford: Blackwell Publishing Ltd.; 2003.

5. Theller HW. Heat sealability of flexible web materials in hot-bar sealing applications. $J$ Plast Film Sheeting. 1989;5:66-93.

6. Stehling FC, Meka P. Heat sealing of semicrystalline polymer films. II. Effect of melting distribution on heat-sealing behavior of polyolefins. J Appl Polym Sci. 1994;51(1):105-119.

7. Nase M, Bach S, Zankel JP, Majschak JP, Grellman W. Ultrasonic sealing versus heat conductive sealing of polyethylene/polybutene-1 peel films. J Appl Polym Sci. 2013;130(1):383-393. 
8. Bach S, Thürling K, Majschak JP. Ultrasonic sealing of flexible packaging films - Principle and characteristics of an alternative sealing method. Packag Technol Sci. 2012;25(4):233248.

9. van Oordt T, Barb Y, Zengerle R, von Stetten F. Lamination of polyethylene composite films by ultrasonic welding: Investigation of peel behavior and identification of optimum welding parameters. J Appl Polym Sci. 2014:40291-1-40291-40297.

10. Stoehr N, Baudrit B, Haberstroh E, Nase M, Heidemeyer P, Bastian M. Ultrasonic welding of plasticized PLA films. J Appl Polym Sci. 2014:41351-1-41351-41358.

11. Planes E, Flandin L. Optimizing the heat sealing parameters of multilayer polymeric films. J Mater Sci. 2011;46:5948-5958.

12. Najarzadeh Z, Ajji A. A novel approach toward the effect of seal process parameters on final seal strength and microstructure of LLDPE. J Adhes Sci Technol. 2014;28(16):15921609.

13. Matthews J, Hicks B, Mullineux G, et al. An empirical into the influence of sealing crimp geometry and process settings on the seal integrity of traditional and biopolymer packaging materials. Packag Technol Sci. 2013;26:355-371.

14. Aithani D, Lockhart H, Auras R, Tansprasert K. Heat sealing measurement by an innovative technique. Packag Technol Sci. 2006;19:245-257.

15. Yuan CS, Hassan A, Ghazali MIH, Ismail AF. Heat sealability of laminated films with LLDPE and LDPE as the sealant materials in bar sealing applications. J Appl Polym Sci. 2007;104(6):3736-3745.

16. Dixon D, Eatock J, Meenan BJ, Morgan M. Application of Design of Experiments (DOE) techniques to process validation in medical device manufacture. J Valid Technol. 2006;12(2):1-9.

17. Hron J, Macák T. Application of design of experiments to welding process of food packaging. Acta Univ Agric Silvic Mendelianae Brun. 2013;LXI(100):909-915.

18. Aiyengar R, Divecha J. Experimental and statistical analysis of the effects of the processing parameters on the seal strength of heat sealed, biaxially oriented polypropylene film for flexible food packaging applications. J Plast Film Sheeting. 2012;28(3):244-256.

19. Bezerra MA, Santelli RE, Oliveira EP, Villar LS, Escaleira LA. Response surface methodology (RSM) as a tool for optimization in analytical chemistry. Talanta. 2008;76:965-977.

20. International A. ASTM F88/F88M-15 Standard Test Method for Seal Strength of Flexible Barrier Materials. West Conshohocken; 2015. www.astm.org.

21. Montgomery DC. Design and Analysis of Experiments. 8th ed. New York: Wiley; 2012.

22. Myers RH, Montgomery DC, Anderson-Cook CM. Response Surface Methodology: Process and Product Optimization Using Designed Experiments. 2nd ed. Hoboken: John Wiley \& Sons, Ltd.; 2011. 
23. Miller A. Subset Selection in Regression. 2nd ed. New York: Chapman and Hall/CRC; 2002.

24. Zhang Z. Variable selection with stepwise and best subset approaches. Ann Transl Med. 2016;4(7):136.

25. Burnham KP, Anderson DR. Multimodal inference: Understanding AIC and BIC in model selection. Sociol Methods Res. 2004;33:261-304.

26. Antony J. Design of Experiments for Engineers and Scientists. Burlington: ButterworthHeinemann; 2003.

27. Jensen WA. Confirmation runs in design of experiments. J Qual Technol. 2016;48(2):162177. 
Table 1: Experimental runs and input parameters of the Box-Behnken design and seal strength $[\mathrm{N} / \mathrm{mm}]$, horn displacement $[\mu \mathrm{m}]$ and energy consumption $[\mathrm{J}]$ responses for the PET/LLDPE-C4 film material.

\begin{tabular}{c|ccc|ccc}
\hline Run & $\begin{array}{c}\text { Time } \\
{[\mathbf{s}]}\end{array}$ & $\begin{array}{c}\text { Force } \\
{[\mathbf{N} / \mathbf{m m}]}\end{array}$ & $\begin{array}{c}\text { Amplitude } \\
{[\boldsymbol{\mu m}]}\end{array}$ & $\begin{array}{c}\text { Strength } \\
{[\mathbf{N} / \mathbf{m m}]}\end{array}$ & $\begin{array}{c}\text { Horn } \\
\text { displacement } \\
{[\boldsymbol{\mu m}]}\end{array}$ & $\begin{array}{c}\text { Energy } \\
\text { consumption [J] }\end{array}$ \\
\hline 1 & 0.2 & 2 & 36 & 1.31 & 10 & 27.75 \\
2 & 0.3 & 4 & 18 & 0.30 & 10 & 21.93 \\
3 & 0.1 & 4 & 36 & 1.76 & 40 & 17.76 \\
4 & 0.2 & 2 & 18 & 0.05 & 10 & 7.50 \\
5 & 0.2 & 4 & 27 & 2.90 & 30 & 21.05 \\
6 & 0.2 & 4 & 27 & 2.43 & 30 & 20.10 \\
7 & 0.1 & 6 & 27 & 2.90 & 80 & 16.30 \\
8 & 0.2 & 4 & 27 & 2.09 & 30 & 17.65 \\
9 & 0.3 & 6 & 27 & 2.11 & 60 & 47.62 \\
10 & 0.2 & 6 & 18 & 1.18 & 40 & 22.58 \\
11 & 0.1 & 2 & 27 & 0.96 & 10 & 7.55 \\
12 & 0.2 & 6 & 36 & 3.52 & 70 & 59.64 \\
13 & 0.3 & 2 & 27 & 0.74 & 10 & 15.61 \\
14 & 0.3 & 4 & 36 & 3.22 & 50 & 55.86 \\
15 & 0.1 & 4 & 18 & 0.52 & 20 & 5.89 \\
\hline
\end{tabular}

Table 2: Significant coefficients, terms, regression significance and equation of the seal strength model for the PET/LLDPE-C4 film.

\begin{tabular}{cccc}
\hline Coefficients & Term & Value & p-value \\
\hline$\beta_{0}$ & Intercept & -2.554 & 0.004 \\
$\beta_{2}$ & Force & 0.416 & 0.001 \\
$\beta_{3}$ & Amplitude & 0.108 & 0.0003 \\
$\beta_{33}$ & Amplitude & -0.007 & 0.08 \\
Regression significance & & & 0.0002 \\
\hline
\end{tabular}

Seal strength $=\beta_{0}+\beta_{2} \times$ Force $+\beta_{3} \times$ Amplitude $+\beta_{33} \times$ Amplitude $^{2}$

Table 3: Significant coefficients, terms, regression significance and equation of the horn displacement model for the PET/LLDPE-C4 film.

\begin{tabular}{cccc}
\hline Coefficients & Term & Value & p-value \\
\hline$\beta_{0}$ & Intercept & -52.911 & 0.0005 \\
$\beta_{2}$ & Force & 13.124 & $<0.0001$ \\
$\beta_{3}$ & Amplitude & 1.250 & 0.0031 \\
$\beta_{23}$ & Force $\times$ Amplitude & 0.417 & 0.1031 \\
Regression significance & & & $<0.0001$ \\
\hline
\end{tabular}


Horn displacement $=\beta_{0}+\beta_{2} \times$ Force $+\beta_{3} \times$ Amplitude $+\beta_{23} \times$ Force $\times$ Amplitude

Table 4: Significant coefficients, terms, regression significance and equation of the seal energy model for the PET/LLDPE-C4 film.

\begin{tabular}{cccc}
\hline Coefficients & Term & Value & p-value \\
\hline$\beta_{0}$ & Intercept & -63.138 & $<0.0001$ \\
$\beta_{1}$ & Time & 0.117 & $<0.0001$ \\
$\beta_{2}$ & Force & 5.483 & 0.0001 \\
$\beta_{3}$ & Amplitude & 1.432 & $<0.0001$ \\
$\beta_{33}$ & Amplitude & 0.0243 \\
$\beta_{12}$ & Time $\times$ Force & 0.029 & 0.0338 \\
$\beta_{13}$ & Time $\times$ Amplitude & 0.006 & 0.0415 \\
Regression significance & & $<0.0001$ \\
\hline Seal energy $=\beta_{0}+\beta_{1} \times$ Time $+\beta_{2} \times$ Force $+\beta_{3} \times$ Amplitude $+\beta_{33} \times$ Amplitude $^{2}+\beta_{12} \times$ Time $\times$ \\
Force $+\beta_{13} \times$ Time $\times$ Amplitude
\end{tabular}

Table 5: Experimental validation of predicted optimum. The predicted optimum and confirmation runs were tested for being significantly different $(\alpha=0.05$ and $\alpha=0.1)$ using the confidence interval approach suggested by Antony $(2003)^{26,27}$.

\begin{tabular}{cccccc}
\hline Parameter & $\begin{array}{c}\text { Predicted } \\
\text { optimum }\end{array}$ & $\begin{array}{c}\text { Mean of } \\
\text { confirmation } \\
\text { runs }(\mathbf{N}=\mathbf{1 0})\end{array}$ & $\begin{array}{c}\text { Standard } \\
\text { deviation } \\
\text { confirmation runs }\end{array}$ & $\begin{array}{c}\text { Significantly } \\
\text { different } \\
(\mathbf{p}<\mathbf{0 . 0 5}) \mathbf{?}\end{array}$ & $\begin{array}{c}\text { Significantly } \\
\text { different } \\
(\mathbf{p}<\mathbf{0 . 1}) \boldsymbol{?}\end{array}$ \\
\hline $\begin{array}{c}\text { Seal strength } \\
{[\mathrm{N} / \mathrm{mm}]}\end{array}$ & 2.32 & 1.94 & 0.42 & Yes & No \\
$\begin{array}{c}\text { Horn } \\
\text { displacement } \\
{[\mu \mathrm{m}]}\end{array}$ & 40.00 & 40.00 & 6.67 & No & No \\
\begin{tabular}{c} 
Energy $[\mathrm{J}]$ \\
\hline
\end{tabular} & 11.66 & 13.68 & 2.13 & Yes & No \\
\hline
\end{tabular}

